\title{
Obstructive sleep apnoea in diabetes - assessment and awareness
}

\author{
IAN W SEETHO ${ }^{1}$, SARAH V O'BRIEN², KEVIN J HARDY², JOHN PH WILDING ${ }^{1}$
}

\begin{abstract}
In 2008, the International Diabetes Federation (IDF) Taskforce on Epidemiology and Prevention released a consensus statement recommending targeted screening for obstructive sleep apnoea (OSA) in people with obesity and type 2 diabetes with classic OSA symptoms, and screening for diabetes, hypertension and dyslipidaemia in those with OSA. We conducted a survey to gain a greater understanding of current practice in relation to the IDF recommendations for the assessment of patients in diabetes clinics in the UK. An online survey that was made accessible to diabetes healthcare professionals with the support of the websites of several diabetes organisations was performed. Most (approximately two-thirds) of diabetes healthcare professionals who responded to this survey were not aware of the IDF recommendations either for diabetes screening in OSA patients or for OSA assessment in type 2 diabetes and obesity. Participants indicated that their local diabetes guidelines did not incorporate assessment for OSA in those deemed to be at risk. Furthermore, most participants perceived OSA investigations to be primarily the domain of the respiratory team rather than the diabetes team. The observations from this survey provide a better understanding of the application and impact of the IDF guidance in diabetes clinics.

Br J Diabetes Vasc Dis 2014;14:105-108
\end{abstract}

Key words: diabetes, sleep disordered breathing, obesity, obstructive sleep apnoea, sleep apnoea.

\section{Introduction}

Changes in sleep breathing patterns termed SDB are associated with obesity and/or type 2 diabetes. SDB is characterised by a spectrum of altered sleep homeostasis that ranges from simple snoring to OSA with excessive daytime sleepiness. In OSA,

Department of Obesity \& Endocrinology, University of Liverpool, UK Department of Diabetes \& Endocrinology, St Helens \& Knowsley Hospitals NHS Trust, UK

Address for correspondence: $\mathrm{Dr}$ lan Seetho

Department of Obesity \& Endocrinology, Clinical Sciences Centre,

University Hospital Aintree, Longmoor Lane, Liverpool L9 7AL, UK

Tel: +44 (0)1515295885 Fax: +44 (0)1515295888

E-mail: iseetho@liv.ac.uk

http://dx.doi.org/10.15277/bjdvd.2014.025
Abbreviations and acronyms
$A B C D$
$\mathrm{AHI}$
CPAP
DSNS
IDF
OSA
RCT
SDB
YDEF

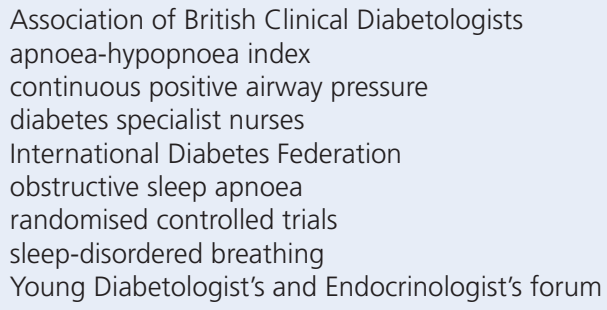

Table 1 AHI for diagnosis and classification of OSA ${ }^{3}$

\begin{tabular}{ll}
\hline Diagnosis & Events per hour \\
Normal & $<5$ \\
Mild OSA & $5-15$ \\
Moderate OSA & $15-30$ \\
Severe OSA & $>30$ \\
AHI = apnoea-hypopnoea index; OSA = obstructive sleep apnoea
\end{tabular}

repeated apnoeas or hypopnoeas occur during sleep. An apnoea is defined as the complete cessation of airflow for at least 10 seconds. A hypopnoea is defined as a reduction in airflow that is followed by an arousal from sleep or a decrease in oxyhaemoglobin saturation. ${ }^{1}$ Formal polysomnography counts the number of apnoeas and hypopnoeas per hour during sleep and the AHI (frequency of apnoea and/or hypopnoea) is used to diagnose and classify the severity of OSA $\mathrm{OS}^{2}$ (Table 1). The frequency of oxygen desaturation episodes and severity of somnolence symptoms are also used. ${ }^{4}$

The estimated prevalence of moderate to severe OSA is $13 \%$ in men and $6 \%$ in women between 30 and 70 years. ${ }^{5}$ The major risk factors for OSA are obesity, gender and increasing age, ${ }^{6}$ and OSA is associated with a clustering of clinical cardio-metabolic manifestations including hypertension and type 2 diabetes. In OSA recurrent episodes of upper airway obstruction and changes in intra-thoracic pressure result in recurrent periodic oxygen desaturations, with frequent sleep arousals and fragmented sleep. 7,8

It has been estimated that up to $40 \%$ of OSA patients will have diabetes, ${ }^{9}$ and in patients with diabetes the prevalence of OSA may be up to $23 \% .{ }^{10}$ Prevalence estimates of OSA in severe obesity have been reported to be $40-90 \% .{ }^{11}$ Patients may be unaware of the association between OSA and type 2 diabetes. The symptoms and signs of OSA may not be perceived relevant to their 
diabetes care, thus their OSA may remain unreported and undiagnosed.

The relationship of OSA with type 2 diabetes has important implications for improving health outcomes given the worldwide prevalence of diabetes mellitus - predicted to increase from 8.3\% in 2013 to $10.1 \%$ in 2035 when patient numbers are expected to reach 592 million. ${ }^{12}$ Despite the absence of RCT data supporting cardiovascular risk reduction with CPAP treatment, we know that cardiovascular disease risk is increased in OSA. ${ }^{13}$ There is also evidence that OSA may be associated with microvascular complications such as diabetic retinopathy, ${ }^{14}$ nephropathy ${ }^{15}$ and neuropathy. ${ }^{16}$

In 2008, the IDF Taskforce on Epidemiology and Prevention released a consensus statement that recommended a targeted approach to screen individuals with type 2 diabetes and obesity for SDB. ${ }^{17,18}$ Briefly, the IDF recommended that healthcare professionals should consider the possibility of OSA in patients with type 2 diabetes and work in tandem with the local sleep service to provide a clinically appropriate process of assessment, referral and intervention. ${ }^{18}$

The purpose of this survey was to gain a greater understanding of current practice in relation to the IDF recommendations for assessment of OSA in patients attending diabetes clinics.

\section{Methods}

An online survey open to all health professionals caring for patients with diabetes in the UK was conducted for four months (December 2013 to March 2014). Data were collected using a questionnaire consisting of seven questions designed in light of the IDF statement (Table 2). The survey was publicly announced on the ABCD and Diabetes UK websites and in the Diabetes UK professional newsletter (Update, December 2013), and on the YDEF website which provided the links to access the online survey. In order to maintain confidentiality all responses were anonymous.

The first two sections of the questionnaire sought to determine demographic data (location of provision of diabetes care and role of the respondent). Questions 1 and 2 aimed to gauge current awareness of the IDF guidance; question 3 to investigate adoption of the IDF recommendations by local diabetes pathways; questions 4 and 5 ascertained the perceived roles for investigating OSA in diabetes patients.

\section{Results}

A total of 62 responses were received, mainly from hospitalbased physicians (Figure 1), and showed that a minority of respondents were aware of the IDF guidelines and their implications for practice, but $78 \%$ of respondents noted that diabetes patients with suspected OSA are investigated by the respiratory team (Table 3). Appendix 1 (available online at www.bjdvd.com) documents questionnaire responses according to role and location. It is noteworthy that all respondents did not answer all questions.

\section{Discussion}

The majority (approximately two-thirds) of diabetes healthcare professionals who responded to this survey were not aware of the IDF recommendations either for diabetes screening in OSA patients or for OSA assessment in type 2 diabetes and obesity. Secondly, most participants indicated that their local diabetes guidelines did not incorporate assessment for OSA in those deemed to be at risk. Thirdly, for the vast majority of participants, assessments were deemed to be primarily the domain of the respiratory team and not the diabetes team.

A beneficial effect of OSA treatment with CPAP in terms of blood pressure reduction was found in patients with type 2 diabetes, ${ }^{19}$ although the research on the of influence of CPAP therapy on glucose homeostasis has yielded mixed findings. ${ }^{20}$ Nevertheless, it has been proposed that there may be a role for a multifaceted approach for these individuals in order to manage their cardio-metabolic risks. ${ }^{21} \mathrm{~A}$ recent observational study of OSA patients with type 2 diabetes assessed clinical outcomes and costeffectiveness of CPAP treatment compared with non-treatment. It was found that CPAP use was associated with significantly lower blood pressure, improved glycaemic control, and was more costeffective than no treatment with CPAP, 22 and a strategy has been proposed to identify, screen and diagnose patients with type 2 diabetes and OSA. ${ }^{23}$

Table 2 Questionnaire on OSA assessment

\begin{tabular}{|c|c|c|c|c|c|}
\hline \multicolumn{6}{|c|}{ Please tick the relevant boxes. } \\
\hline Location: & Teaching/University Hospital & District General Hospital $\square$ & GP Practice & & \\
\hline \multirow[t]{2}{*}{ Role: } & Consultant $\square$ & Diabetes Specialist Nurse $\square$ & Other & & \\
\hline & & & $\mathbf{Y}$ & $\mathbf{N}$ & Don't Know \\
\hline \multicolumn{3}{|c|}{ 1. I know IDF guidance to screen for diabetes in OSA? } & $\square$ & $\square$ & $\square$ \\
\hline \multicolumn{3}{|c|}{ 2. I know IDF guidance to screen for OSA in high risk patients with diabetes \& obesity? } & $\square$ & $\square$ & $\square$ \\
\hline \multicolumn{3}{|c|}{ 3. Our local diabetes guidelines recommend OSA screening in diabetes patients at risk of OSA? } & $\square$ & $\square$ & $\square$ \\
\hline \multicolumn{3}{|c|}{ 4. Local people with diabetes suspected of OSA are investigated by diabetes team? } & $\square$ & $\square$ & $\square$ \\
\hline \multicolumn{3}{|c|}{ 5. Local people with diabetes suspected of OSA are investigated by respiratory team? } & $\square$ & $\square$ & $\square$ \\
\hline
\end{tabular}


Figure 1. Questionnaire results showing location of work and role of respondents $(n=62)$.
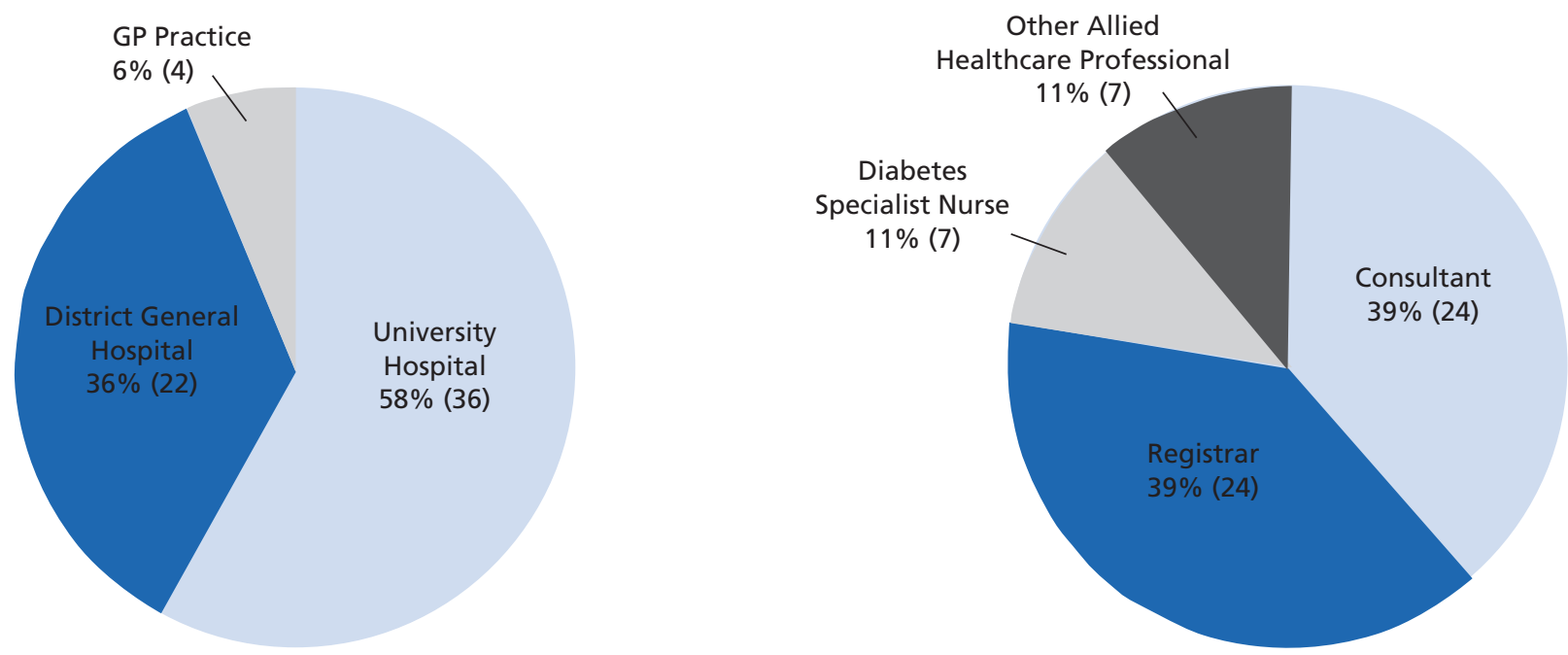

Table 3 Responses to questions 1-5. Total number of respondents $=62$ *

\section{Question}

1. I know IDF guidance to screen for diabetes in OSA?

2. I know IDF guidance to screen for OSA in high risk patients with diabetes \& obesity?

3. Our local diabetes guidelines recommend OSA screening in diabetes patients at risk of OSA?

4. Local people with diabetes suspected of OSA are investigated by diabetes team?

5. Local people with diabetes suspected of OSA are investigated by respiratory team?

\section{Responses}

Yes

No

$32 \%(n=19)$

$38 \%(n=23)$

$38 \%(n=23)$

$34 \%(n=21)$

$19 \%(n=12)$

$45 \%(n=28)$

$12 \%(n=7)$

$78 \%(n=48)$

$67 \%(n=40)$

$21 \%(n=13)$

$3 \%(n=2)$

$19 \%(n=12)$

*Some respondents did not answer all questions: 2 skipped question 1; 1 skipped question 2; 2 skipped question 4.

The Epworth Sleepiness scale is a validated questionnaire to assess the severity of sleepiness symptoms and is a simple screening tool that could be used for patients suspected of SDB. However, it should be borne in mind that although hypersomnolence symptoms may relate to micro-arousals and to changes in sleep architecture, it is non-specific and not always associated with OSA. Therefore it is not sufficiently discriminating to diagnose OSA. ${ }^{24}$ Depending on services available, a referral for sleep studies or to the relevant sleep team for further assessment may be necessary. Lifestyle recommendations such as weight reduction for overweight or obese patients, smoking cessation, avoidance of sedatives, decreasing alcohol consumption and proper sleep hygiene may be recommended.

The treatment of OSA aims to reduce daytime sleepiness. CPAP is recommended as a treatment option for individuals with moderate or severe symptomatic OSA given the effects on blood pressure, implications for quality of life and driving safety. ${ }^{25}$ There is evidence that non-sleepy OSA patients treated with CPAP have not shown effective decreases in blood pressure and it is possible that non-sleepy asymptomatic OSA patients may face a different level of risk from those who are sleepy. ${ }^{26}$

This study has several limitations. Despite public announcements of the survey and engaging the help of organisations including the $A B C D$, the YDEF and Diabetes UK, which has an estimated 6,000 professional members (Richard Elliot, Personal Communication, 17 June 2014), there were only 62 respondents, so there is likely to be a significant non-response bias given the limited sample size. A higher response rate using a validated questionnaire would increase confidence in the generalisability of the findings.

Nevertheless awareness of OSA and taking it into consideration as part of our holistic patient assessment are very important. 


\section{Key messages}

- OSA is a common co-morbidity in diabetes and obesity

- A history of snoring, excessive daytime somnolence and witnessed apnoeic events may be suggestive of OSA

- A pro-active approach is encouraged to identify patients at risk of OSA

\section{Conflict of interest None}

Acknowledgements We would like to thank Dr Richard Elliot, Diabetes UK for assisting in the conduct of the research. We also thank Diabetes UK, the Association of British Clinical Diabetologists, and the Young Diabetologists and Endocrinologists' Forum (YDEF) for supporting this project.

Funding This research was supported by the University of Liverpool, University Hospital Aintree and St Helens \& Knowsley Teaching Hospitals NHS Trust.

\section{References}

1. Punjabi NM. The epidemiology of adult obstructive sleep apnea. Proc Am Thor Soc 2008;5:136-43. http://dx.doi.org/10.1513/pats.200709-155MG

2. Caples SM, Gami AS, Somers VK. Obstructive sleep apnea. Ann Intern Med 2005; 142:187-97. http://dx.doi.org/10.7326/0003-4819-142-3-200502010-00010

3. Flemons WW, Buysse D, Redline $S$, et al. Sleep-related breathing disorders in adults: Recommendations for syndrome definition and measurement techniques in clinical research. Sleep 1999;22:667-89.

4. Flemons WW, Littner MR, Rowley JA, et al. Home diagnosis of sleep apnea: a systematic review of the literature. An evidence review cosponsored by the American Academy of Sleep Medicine, the American College of Chest Physicians, and the American Thoracic Society. Chest 2003;124:1543-79. http://dx.doi.org/10.1378/chest.124.4.1543

5. Peppard PE, Young $T$, Barnet JH, et al. Increased prevalence of sleepdisordered breathing in adults. Am J Epidemiol 2013;177:1006-14. http://dx.doi.org/10.1093/aje/kws342

6. Malhotra A, White DP. Obstructive sleep apnoea. Lancet 2002;360:23745. http://dx. doi.org/10.1016/S0140-6736(02)09464-3

7. Young T, Palta M, Dempsey J, et al. The occurrence of sleep-disordered breathing among middle-aged adults. N Eng J Med 1993;328:1230-5. http://dx.doi.org/10.1056/NEJM199304293281704

8. Tasali E, Ip MSM. Obstructive sleep apnea and metabolic syndrome: alterations in glucose metabolism and inflammation. Proc Am Thor Soc 2008;5:207-17. http://dx.doi.org/10.1513/pats.200708-139MG

9. Meslier N, Gagnadoux F, Giraud P, et al. Impaired glucose-insulin metabolism in males with obstructive sleep apnoea syndrome. Eur Resp J
2003;22:156-60. http://dx.doi.org/10.1183/09031936.03.00089902

10. West SD, Nicoll DJ, Stradling JR. Prevalence of obstructive sleep apnoea in men with type 2 diabetes. Thorax 2006;61:945-50. http://dx.doi.org/10.1136/thx.2005.057745

11. Schwartz AR, Patil SP, Laffan AM, et al. Obesity and obstructive sleep apnea: pathogenic mechanisms and therapeutic approaches. Proc Am Thor Soc 2008;5:185-92. http://dx.doi.org/10.1513/pats.200708-137MG

12. IDF Diabetes Atlas, 6th edn. International Diabetes Federation, Brussels, 2013 (http://www.idf.org/diabetesatlas/download-book; accessed June 2014).

13. Seicean S, Strohl KP, Seicean A, et al. Sleep disordered breathing as a risk of cardiac events in subjects with diabetes mellitus and normal exercise echocardiographic findings. Am J Cardiol 2013;111:1214-20. $\mathrm{http}: / / \mathrm{dx}$.doi.org/10.1016/j.amjcard.2012.12.053

14. West SD, Groves DC, Lipinski HJ, et al. The prevalence of retinopathy in men with Type 2 diabetes and obstructive sleep apnoea. Diabet Med 2010;27:423-30. http://dx.doi.org/10.1111/j.1464-5491.2010.02962.x

15. Tahrani AA, Ali A, Raymond NT, et al. Obstructive sleep apnea and diabetic nephropathy. A cohort study. Diabetes Care 2013;36:3718-25. http://dx.doi.org/10.2337/dc13-0450

16. Tahrani AA, Ali A, Raymonds NT, et al. Obstructive sleep apnea and diabetic neuropathy. A novel association in patients with type 2 diabetes. Am J Resp Crit Care Med 2012;186:434-41. http://dx.doi.org/10.1164/rccm.201112-21350C

17. Shaw JE, Punjabi NM, Wilding JP, et al. Sleep-disordered breathing and type 2 diabetes - A report from the International Diabetes Federation Taskforce on Epidemiology and Prevention. Diab Res Clin Pract 2008; 81:2-12. http://dx.doi.org/10.1016/j.diabres.2008.04.025

18. International Diabetes Federation. Belgium. The IDF Consensus Statement on Sleep Apnoea and type 2 diabetes. 2008. (http://www.idf.org/ webdata/docs/APNOEA_final.pdf (Accessed June 2014).

19. Myhill PC, Davis WA, Peters KE, et al. Effect of continuous positive airway pressure therapy on cardiovascular risk factors in patients with type 2 diabetes and obstructive sleep apnea. JCEM 2012;97:4212-18.

20. Surani S, Subramanian S. Effect of continuous positive airway pressure therapy on glucose control. World J Diab 2012;3:65-70. http://dx.doi.org/10.4239/wjd.v3.i4.65

21. Pepin JL, Tamisier R, Levy P. Obstructive sleep apnoea and metabolic syndrome: put CPAP efficacy in a more realistic perspective. Thorax 2012;67:1025-27. http://dx.doi.org/10.1136/thoraxjnl-2012-202807

22. Guest JF, Panca M, Sladkevicius E, et al. Clinical outcomes and costeffectiveness of continuous positive airway pressure to manage obstructive sleep apnea in patients with type 2 diabetes in the UK. Diabetes Care 2014;37:1263-71. http://dx.doi.org/10.2337/dc13-2539

23. Idris I, Hall AP, O'Reilly J, et al. Obstructive sleep apnoea in patients with type 2 diabetes: aetiology and implications for clinical care. Diab Obes Metab 2009:11:733-41. http://dx.doi.org/10.1111/j.1463-1326.2009.01045.x

24. Strohl KP, Redline S. Recognition of obstructive sleep apnea. Am J Resp Crit Care Med 1996;154(2):279-89. http://dx.doi.org/10.1164/ajrccm.154.2.8756795

25. Giles TL, Lasserson TJ, Smith BJ, et al. Continuous positive airways pressure for obstructive sleep apnoea in adults. Cochrane Database of Syst Rev 2006;19(3):CD001106.

26. Montserrat JM, Garcia-Rio F, Barbe F. Diagnostic and therapeutic approach to nonsleepy apnea. Am J Resp Crit Care Med 2007;176(1):6-9. http://dx.doi.org/10.1164/rccm.200606-795PP 


\section{Appendix 1.}

\section{Questionnaire results by role and location of} respondents

\begin{tabular}{ll}
\hline Role and location & No of respondents \\
Consultant DGH & 9 \\
Consultant Uni Hosp & 15 \\
Registrar DGH & 10 \\
Registrar University Hosp & 14 \\
DSN DGH & 1 \\
DSN University Hospital & 4 \\
DSN GP Practice & 2 \\
AHP University Hospital & 3 \\
AHP DGH & 2 \\
AHP GP Practice & 2 \\
Total & 62
\end{tabular}

Q1 Awareness of IDF guidance to screen for diabetes in people with OSA

\begin{tabular}{lllll}
\hline Role and location & Yes & No & Don't Know & Skipped \\
Consultant DGH & 5 & 2 & 2 & 0 \\
Consultant Uni Hosp & 7 & 3 & 4 & 1 \\
Registrar DGH & 1 & 7 & 1 & 1 \\
Registrar Uni Hosp & 2 & 5 & 7 & 0 \\
DSN DGH & 0 & 0 & 1 & 0 \\
DSN Uni Hosp & 1 & 2 & 1 & 0 \\
DSN GP Prac & 1 & 0 & 1 & 0 \\
AHP Uni Hosp & 0 & 2 & 1 & 0 \\
AHP DGH & 2 & 0 & 0 & 0 \\
AHP GP Prac & 0 & 2 & 0 & 0 \\
Total & 19 & 23 & 18 & 2
\end{tabular}

Q2 Awareness of IDF guidance to screen at-risk patients with diabetes \& obesity for OSA

\begin{tabular}{lllll}
\hline Role and location & Yes & No & Don't Know & Skipped \\
Consultant DGH & 5 & 2 & 2 & 0 \\
Consultant Uni Hosp & 4 & 5 & 5 & 1 \\
Registrar DGH & 2 & 6 & 2 & 0 \\
Registrar Uni Hosp & 4 & 6 & 4 & 0 \\
DSN DGH & 0 & 0 & 1 & 0 \\
DSN Uni Hosp & 2 & 1 & 1 & 0 \\
DSN GP Prac & 2 & 0 & 0 & 0 \\
AHP Uni Hosp & 0 & 2 & 1 & 0 \\
AHP DGH & 2 & 0 & 0 & 0 \\
AHP GP Prac & 0 & 1 & 1 & 0 \\
Total & 21 & 23 & 17 & 1
\end{tabular}

Q3 Do local diabetes guidelines recommend OSA screening in diabetes patients at-risk of OSA?

\begin{tabular}{lllll}
\hline Role and location & Yes & No & Don't Know & Skipped \\
Consultant DGH & 1 & 5 & 3 & 0 \\
Consultant Uni Hosp & 1 & 9 & 5 & 0 \\
Registrar DGH & 2 & 6 & 2 & 0 \\
Registrar Uni Hosp & 5 & 4 & 5 & 0 \\
DSN DGH & 0 & 1 & 0 & 0 \\
DSN Uni Hosp & 0 & 2 & 2 & 0 \\
DSN GP Prac & 1 & 0 & 1 & 0 \\
AHP Uni Hosp & 1 & 0 & 2 & 0 \\
AHP DGH & 1 & 0 & 1 & 0 \\
AHP GP Prac & 0 & 1 & 1 & 0 \\
Total & 12 & 28 & 22 & 0
\end{tabular}

Q4 Are patients with diabetes suspected of OSA investigated by the diabetes team?

\begin{tabular}{lllll}
\hline Role and location & Yes & No & Don't Know & Skipped \\
Consultant DGH & 2 & 6 & 0 & 1 \\
Consultant Uni Hosp & 1 & 14 & 0 & 0 \\
Registrar DGH & 0 & 8 & 2 & 0 \\
Registrar Uni Hosp & 3 & 8 & 2 & 1 \\
DSN DGH & 0 & 1 & 0 & 0 \\
DSN Uni Hosp & 1 & 1 & 2 & 0 \\
DSN GP Prac & 0 & 0 & 2 & 0 \\
AHP Uni Hosp & 0 & 0 & 3 & 0 \\
AHP DGH & 0 & 1 & 1 & 0 \\
AHP GP Prac & 0 & 1 & 1 & 0 \\
Total & 7 & 40 & 13 & 2
\end{tabular}

Q5 Are patients with diabetes suspected of OSA investigated by the respiratory team?

\begin{tabular}{lllll}
\hline Role and location & Yes & No & Don't Know & Skipped \\
Consultant DGH & 7 & 2 & 0 & 0 \\
Consultant Uni Hosp & 13 & 0 & 2 & 0 \\
Registrar DGH & 9 & 0 & 1 & 0 \\
Registrar Uni Hosp & 12 & 0 & 2 & 0 \\
DSN DGH & 1 & 0 & 0 & 0 \\
DSN Uni Hosp & 2 & 0 & 2 & 0 \\
DSN GP Prac & 1 & 0 & 1 & 0 \\
AHP Uni Hosp & 1 & 0 & 2 & 0 \\
AHP DGH & 1 & 0 & 1 & 0 \\
AHP GP Prac & 1 & 0 & 1 & 0 \\
Total & 48 & 2 & 12 & 0
\end{tabular}

